\title{
Zika Induced Meningoencephalitis in a Ruxolitinib Treated Patient with Secondary Myelofibrosis
}

\author{
Ahmad Al Ghoche ${ }^{1}$, Jean Pegliasco ${ }^{1}$, Jessica Anne-Marie-Sainte ${ }^{1}$, Julien Cuziat ${ }^{2}$, Lucas Meyer ${ }^{3}$, Fatiha \\ Najioullah $^{4}$, Jean Côme Meniane ${ }^{1^{*}}$ and Samy Chraïbi ${ }^{1}$
}

\author{
${ }^{1}$ Clinical Hematology Department, University Hospital of Martinique, France \\ ${ }^{2}$ Infectious and Tropical Diseases Department, University Hospital of Martinique, France \\ ${ }^{3}$ Hematology Laboratory, University Hospital of Martinique, France \\ ${ }^{4}$ Virology Laboratory, University Hospital of Martinique, France
}

*Corresponding author: Jean Côme Meniane, Clinical Hematology Department, University Hospital of Martinique, France, Tel: +0596-552-141, E-mail: Jean-Come.Meniane@chu-martinique.fr

\begin{abstract}
We describe here the first case of a patient with post-ET myelofibrosis treated with ruxolitinib at French West Indies complicated with zika induced meningoencephalitis. Patient presented with fever, confusion along with conjunctivitis, diffuse joints pain and skin rash. PCR was positive for Zika virus in blood, urine and cerebrospinal fluid. Diagnosis of Zika induced meningoencephalitis was confirmed. The inhibition of the JAK/STAT receptor induced by ruxolitinib is implicated in inflammation and immune response and has been associated with several forms of viral complication. Patients under ruxolitinib should be considered at high risk of arboviruses complications in endemics areas.
\end{abstract}

\section{Keywords}

Zika, Meningoencephalitis, Ruxolitinib, Myelofibrosis, Essential thrombocythemia

\section{Case Report}

Ruxolitinib, a JAK1/2 inhibitor, used in the treatment of myelofibrosis and polycythemia vera, has been associated several neurologic manifestations. Zika virus has also been implicated in several forms of neurologic involvement. Hereby we describe the first case of Zika induced meningoencephalitis in a patient with secondary myelofibrosis being treated with ruxolitinib in arboviruses endemic area.

We report a case of a 75-year-old patient at the time of presentation, in a good Performance Status (PS 0) since diagnosis 26-years-ago with Essential Thrombocythemia (ET), being treated with hydroxyurea, a cytoreductive agent, at a dose of $2 \mathrm{~g} /$ day. In November 2015, patient presented to our Hematology unit with severely altered general status, he was bedbound and therefore classified as performance status 4 on ECOG scale. Physical exam revealed diffuse nonspecific bone pain and laboratory test showed anemia with hemoglobin of $6.6 \mathrm{~g} / \mathrm{dL}$, and LDH of $557 \mathrm{UI} / \mathrm{L}$ (Normal range between 135 and $214 \mathrm{UI} / \mathrm{L}$ ), with $16 \%$ erythroblasts on blood count and tear drop cells on peripheral blood smear. Bone marrow biopsy confirmed the suspected diagnosis of transformation into post-ET myelofibrosis. MPL mutation was positive (exon 10). Bone marrow aspirate showed only $1 \%$ of blasts and karyotype was complex. DIPSS score consisting of age, white blood count, blast percentage, hemoglobin and constitutional symptoms was 5 and patient was classified as high risk (high risk defined as a score higher than 3). Patient was started on transfusion therapy with supportive care and pain management with only mild improvement in bone pain, so ruxolitinib was added at a dose of $15 \mathrm{mg}$ twice daily in February 2016, after which patient had a major improvement in his pain and performance status and was able to move and accomplish his daily living with only mild support needed which was the expected goal of adding targeted therapy.

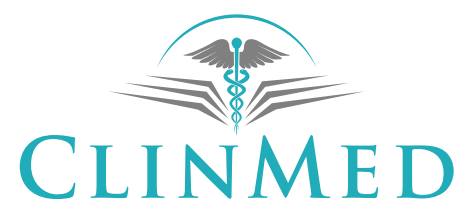

INTERNATIONAL LIBRARY

Citation: Al Ghoche A, Pegliasco J, Anne-Marie-Sainte J, Cuziat J, Meyer L, et al. (2017) Zika Induced Meningoencephalitis in a Ruxolitinib Treated Patient with Secondary Myelofibrosis. Int J Blood Res Disord 4:028. doi.org/10.23937/2469-5696/1410028

Received: August 23, 2017: Accepted: October 26, 2017: Published: October 28, 2017

Copyright: (C) $2017 \mathrm{Al}$ Ghoche A, et al. This is an open-access article distributed under the terms of the Creative Commons Attribution License, which permits unrestricted use, distribution, and reproduction in any medium, provided the original author and source are credited. 
In April 2016, patient was admitted to the Emergency Department in Martinique University Hospital with altered general status and severe headache along with photophobia that started 24 hours before seeking medical advice. Patient's wife stated that he was complaining one week before presentation of conjunctivitis with diffuse joints pain and developed a skin rash over his body. Physical exam showed a febrile normotensive patient, confused with severe neck stiffness. Laboratory tests were within normal range except for a C-Reactive Protein (CRP) of $80 \mathrm{mg} / \mathrm{L}$ (negative being less than $5 \mathrm{mg} / \mathrm{L}$ ), anemia with hemoglobin level at $8.5 \mathrm{~g} / \mathrm{dL}$ and normal platelet count at $180 \mathrm{G} / \mathrm{L}$. MRI showed grade III leukoaraiosis with diffuse meningeal enhancement. Lumbar puncture was done and Cerebro-Spinal Fluid (CSF) was acellular with a protein level of $0.51 \mathrm{~g} / \mathrm{L}$ (normal range between 0.15 and $0.4 \mathrm{~g} / \mathrm{L}$ ), and virology tests were performed. Patient was admitted to the hematology department and was started on acyclovir dose adapted for herpes meningoencephalitis and supportive care. Ruxolitinib was stopped. Twenty four hours after admission, patient had a quick improvement in his clinical status with disappearance of all neurologic manifestations. Virology tests on blood samples drawn on admission showed negative IgM, positive IgG and negative PCR for Chikungunya Virus (CHIKV). Dengue Virus (DENGV) serology was negative for both IgG and IgM and the PCR was also negative. PCR for Zika Virus (ZIKV) was positive in all three Cerebrospinal Fluid (CSF), blood and urine samples. CSF PCR was negative for Herpes Simplex Virus (HSV) and Varicella-Zoster (VZV). So diagnosis was confirmed as Zika induced meningoencephalitis. Ruxolitinib was reintroduced to hospital discharge 1 week after admission and we stopped acyclovir twenty four hours after. Two months after the neurological episode, the patient died of septic shock in a context of secondary acute leukemia and no further therapy was available for this elderly unfit patient.

Ruxolitinib is a double JAK inhibitor, anti-JAK 1 and 2, approved in 2011 for the treatment of myeloproliferative neoplasms especially myelofibrosis. Those patients are already highly immunocompromised. Inhibition of the JAK/STAT receptor is implicated in inflammation and immune response [1] and significantly increases the risk of infectious diseases in myelofibrosis as recently reported in a retrospective study [2]. Ruxolitinib's increased risk of opportunistic infections may be linked to the suppressive effect on the number and function of natural killer cells and dendritic cells. Ruxolitinib has changed the course of disease treatment by giving additional management pathway to symptomatic patients. Bone marrow transplantation still the only curative approach but many patients are not candidate because of age and comorbidities and for these patients ruxolitinib is associated with overall survival compared to best available therapy [3].
However this drug has been associated with several forms of viral complications such as progressive multifocal leukoencephalopathy [4], disseminated herpes simplex virus, VZV meningoencephalitis [5] and CMV retinitis [6] and subsequently ruxolitinib has not been recommended in the setting of active infection. Apart from recommended screening for tuberculosis in endemic areas before using JAK-2 inhibitor, no specific infectious screening recommendations are available. On the other hand, in addition to the spectrum of clinical manifestations associated with infection, ZIKV has a known brain tropism with several reported cases of ZIKV induced encephalitis and Guillain-Barre syndrome in both immunocompetent and immunocompromised patients [7-10]. High risk post-ET myelofibrosis has poor overall survival. Our patient had progressive disease with only 7 months from fibrotic transformation to acute leukemia state and then death, compared with 2 years for the median overall survival of high risk post-ET myelofibrosis [11].

Since we are located in French West Indies, known as endemic area for arboviruses and because of recently described cases of meningoencephalitis, we started to test for the presence of those viruses in patients with unexplained central nervous system disorders. Ruxolitinib is newly approved immunosuppressive agent but more and more prescribed, therefore clinicians should be aware of this new risk factor of arboviruses diseases in endemic area.

\section{References}

1. Villarino AV, Kanno Y, O'Shea JJ (2017) Mechanisms and consequences of Jak-STAT signaling in the immune system. Nat Immunol 18: 374-384.

2. Polverelli N, Breccia M, Benevolo G, Martino B, Tieghi A, et al. (2017) Risk factors for infections in myelofibrosis: Role of disease status and treatment. A multicenter study of 507 patients. Am J Hematol 92: 37-41.

3. Harrison CN, Vannucchi AM, Kiladjian JJ, Al-Ali HK, Gisslinger $\mathrm{H}$, et al. (2017) Long-term findings from COMFORT-II, a phase 3 study of ruxolitinib vs. best available therapy for myelofibrosis. Leukemia 31: 775.

4. Wathes R, Moule S, Milojkovic D (2013) Progressive multifocal leukoencephalopathy associated with ruxolitinib. $\mathrm{N}$ Engl J Med 369: 197-198.

5. Eyal O, Flaschner M, Ben Yehuda A, Rund D (2017) Varicella-zoster virus meningoencephalitis in a patient treated with ruxolitinib. Am J Hematol 92: E74-E75.

6. von Hofsten J, Johnsson Forsberg M, Zetterberg M (2016) Cytomegalovirus retinitis in a patient who received ruxolitinib. N Engl J Med 374: 296-297.

7. Carteaux $G$, Maquart $M$, Bedet $A$, Contou $D$, Brugières $P$, et al. (2016) Zika Virus Associated with Meningoencephalitis. N Engl J Med 0: null.

8. Rozé B, Najioullah F, Signate A, Apetse K, Brouste Y, et al. (2016) Zika virus detection in cerebrospinal fluid from two patients with encephalopathy, Martinique, February 2016. Euro Surveill 21.

9. Schwartzmann PV, Ramalho LN, Neder L, Vilar FC, Ayub-Ferreira SM, et al. (2017) Zika Virus Meningoenceph- 
alitis in an Immunocompromised Patient. Mayo Clin Proc 92: 460-466.

10. Bautista LE, Sethi AK (2016) Association between Guillain-Barré syndrome and Zika virus infection. Lancet 387: 2599-2600.
11. Passamonti F, Giorgino T, Mora B, Guglielmelli P, Rumi E, et al. (2017) A clinical-molecular prognostic model to predict survival in patients with post polycythemia vera and post essential thrombocythemia myelofibrosis. Leukemia. 